\title{
Tourist's Perception on the Service Quality of Sheqi Ancient Town: A Demographic Perspective
}

\author{
Juan Zhang ${ }^{1 *} \quad$ Chanchai Bunchapttanasakda ${ }^{2}$ \\ 1.PhD Candidate, School of Management, Shinawatra University, Thailand \\ 2.Assistant Professor, School of Management, Shinawatra University, Thailand
}

\begin{abstract}
The main purpose of this study is to identify tourists' perception on the quality of tourism services of an ancient town, Sheqi, in central part of China from demographic perspective. A survey of 1,389 tourists visited an ancient town in center part of China was conducted as the basis for analysis. Descriptive analysis, $\mathrm{T}$ test and one-way ANOVA are employed to profile the status quo of tourists' perceived quality and examine the differences between different groups of tourists with different demographic characteristics regarding gender, ages, monthly income, occupations, and highest levels of education. The results showed that tourists have a high perception and evaluation on the quality of tourism service in Sheqi ancient town, and tourists with different age, monthly income, and education level have different perception on the tourism service significantly.
\end{abstract}

Keywords: Perceived Quality; SERVQUAL Model; Demographics; Sheqi Ancient Town

DOI: $10.7176 /$ JTHS/44-04

Publication date:October $31^{\text {st }} 2019$

\section{Introduction}

Perceived quality was defined as the customer's perception on the overall quality of a product or service (Aaker, 2009). In tourism field, practitioners and experts also paid much attention to perceived quality and relevant concepts such as tourist satisfaction and destination loyalty (Wang \& Mei, 2006). Generally, tourists' perception on the quality of a attraction is the determinant of their choice, evaluation and satisfaction on the specific attraction. Baker \& Crompton (2000) suggested that high perceived quality and high tourist satisfaction result in tourist loyalty and revisit, more tolerance of price increasing and rising fame of the attraction. It is very helpful for the destination to attract both new tourists through positive word-of-mouth and new public tax investment and private investment to improve the development of the destination.

In China, there are a lot of historical and cultural ancient cities, towns, and villages, which has experienced the fluctuation of boom and bust in history with much heritage and civilization left. With $\mathrm{h}$ the historical and cultural tourism becomes more and more popular worldwide(Chen \& Chen, 2010), to create employment opportunities and prompt the transformation and upgrading of economic structure, local governments of these historical places develop historical and cultural tourism by making use of these historical resources. The revitalization of historic places led by tourism has driven the boom of historical and cultural tourism in China. To identify tourists' perceived quality of historical and cultural destinations will provide managers of such attractions with information necessary for destination marketing decision making. Therefore, the first objective of this study is to investigate tourists' perception of service quality provided by historical and cultural attractions taking an ancient town in central part of China, namely Sheqi, as an example. The second objective is to find out whether demographics of tourists influence their perceptions on the service quality provided by the specific attraction.

\section{Operationalization of Construct}

Perceived quality is the real feeling and perception of customers on the quality of the product or service they purchased. Researchers attached great importance to perceived quality of service in the tourism context. A lot of studies have been done on tourists' perceptions of service quality as they travel (Chen, Huang,\& Petrick, 2016; Su, Swanson, \& Chen, 2016), and perceived quality was identified as a critical determinant of tourist's satisfaction (Wang, 2011).

A well-known conceptual model for service quality, SERVQUAL, was proposed initially by Parasuraman, Zeithaml and Berry in 1985, and redefined in 1988 by subdividing it into five dimensions: reliability, responsiveness,, empathy, assurance and tangibility. Based on the SERVQUAL model, other models for perceived service quality of different sectors were developed one by one. Wu and $\mathrm{Li}$ (2015) proposed the SERVPERF model to evaluate visitors' perceptions of museum service. HISTOQUAL, involving the five factors of responsiveness, tangibles, communications, consumables and empathy, was established to investigate perceived quality in the cultural and heritage tourism context (Chen \& Shi, 2008). And MUSEQUAL was developed to assess museum visitor's experience of service and their satisfaction (Hsieh, Park, \& Hitchcock, 2015).

In this study, to measure the perception of the tourists on the quality of the attraction and the services provided, questions were adapted from SERVQUAL Battery (Parasuraman, 1994). The instrument of SERVQUAL were widely employed in service quality researches (Kang, Jame \& Alexandris, 2002) and the reliability and validity of 
the instrument were proven by numerous studies (Lam \& Woo, 1997; Randheer et al., 2011). According to the Evaluation and Measurement System of Tourism Attractions in China released by China's National Tourism Administration, 25 items were developed to measure the perceived quality of the specific historical and cultural destination, an ancient town (Sheqi) in China.

\section{Methods}

Perceived quality in this study is a latent variables that can not be measured directly, hence, observed variables were designed in the questionnaire as the survey instrument based on thorough literature review and in-depth interview with the peculiarities of the destination taken into account. The questionnaire included two parts. In part A, there were five main sections to explore the five dimensions of the perceived quality of the attraction with each dimension including 5 items. Respondents were required to determine the degree to which each statement reflects their perception on the attraction and the services provided. All items used a five-point Likert-type scale ranging from $1=$ never to $5=$ always. The total Cronbach $\alpha$ for the measurement was .984 , which indicated good internal consistency of the construct. Part B consisted of 11 questions reflecting the respondents' demographic information and travel behavior.

\subsection{Sample design and data collection}

Semi-constructed survey questionnaire was used to collect data at an ancient town, namely Sheqi, located in Henan province, middle part of China, during May, 2019. A convenience sampling method was adopted because of limited time and manpower. The questionnaire was distributed at the exit and the service center of the attraction. Visitors who finished their visiting of the ancient town were asked about their willingness to participate the questionnaire survey. If they were willing to, they were asked to complete the questionnaire either on paper or on the cellphone by scanning the QR code. A total number of 1,500 questionnaires were distributed and 1,389 were completed. Thus, the response rate was 92.6 per cent.

After questionnaires were collected, SPSS 21. was used to do data analysis. Descriptive analysis was conducted to identify tourists' perception on the service quality provided, T test and ANOVA anaysis were employed to explore whether demographic and travelling behavior had impact on perceived quality.

\subsection{Characteristics of the respondents}

The sample characteristics appeared in Table 1 . There were slightly more female visitors $(51.6 \%)$ than male. The majority of respondents were between age of 18 to 49 (91.6\%) coming from Nanyang district and other districts of Henan province $(70.8 \%)$, and had at least three year of college education $(82.5 \%)$ with monthly income less than 5000 Yuan $(72.5 \%)$. Many respondents knew about the ancient town by recommendation of family and friends (46.2) and visited with friends and family members (64.9\%). 
Table 1. Respondent characteristics and descriptive statistics

\begin{tabular}{|c|c|c|c|}
\hline Variable & Category & Frequency & Percentage \\
\hline \multirow[b]{2}{*}{ Gender } & Male & 672 & $48.4 \%$ \\
\hline & Female & 717 & $51.6 \%$ \\
\hline \multirow{6}{*}{ Age } & Under 18 & 53 & $3.8 \%$ \\
\hline & $18-29$ & 468 & $33.7 \%$ \\
\hline & $30-39$ & 429 & $30.9 \%$ \\
\hline & $40-49$ & 376 & $27.0 \%$ \\
\hline & $50-59$ & 56 & $4.0 \%$ \\
\hline & 60 and up & 7 & $0.5 \%$ \\
\hline \multirow{5}{*}{ Highest level of education } & Less than High school & 25 & $1.8 \%$ \\
\hline & Equal to high school & 218 & $15.7 \%$ \\
\hline & Associate degree & 434 & $31.2 \%$ \\
\hline & Bachelor degree & 529 & $38.1 \%$ \\
\hline & Master's and Doctoral degree & 183 & $13.2 \%$ \\
\hline \multirow{5}{*}{ Monthly income } & Less than 3,000 Yuan & 605 & $43.6 \%$ \\
\hline & 3,000 Yuan-4,999 Yuan & 401 & $28.9 \%$ \\
\hline & 5,000 Yuan-7,999 Yuan & 232 & 16.75 \\
\hline & 8,000 Yuan-10,000 Yuan & 79 & $5.7 \%$ \\
\hline & Above 10,000 Yuan & 72 & $5.2 \%$ \\
\hline \multirow{4}{*}{ Region coming from } & Local & 336 & $24.2 \%$ \\
\hline & Nanyang District & 429 & 30.9 \\
\hline & Other districts of Henan Province & 554 & $39.9 \%$ \\
\hline & Outside of Henan Province & 70 & $5.0 \%$ \\
\hline \multirow{4}{*}{ Number of times visited } & Only once & 726 & $52.3 \%$ \\
\hline & 2 times & 144 & $10.4 \%$ \\
\hline & 3 times & 76 & $5.5 \%$ \\
\hline & Many times & 443 & $31.9 \%$ \\
\hline \multirow{6}{*}{ Information source } & Referral from friends and family & 642 & $46.2 \%$ \\
\hline & Internet & 188 & $13.5 \%$ \\
\hline & Advertising and propaganda & 218 & $15.7 \%$ \\
\hline & Travel agent & 24 & $1.7 \%$ \\
\hline & Magazine article & 18 & $1.3 \%$ \\
\hline & others & 299 & $21.5 \%$ \\
\hline \multirow{5}{*}{ Travel party size } & 1 person & 264 & $19.0 \%$ \\
\hline & 2 persons & 218 & $15.7 \%$ \\
\hline & 3 persons & 332 & $23.9 \%$ \\
\hline & 4 persons & 263 & $18.9 \%$ \\
\hline & 5 persons or above & 312 & $22.5 \%$ \\
\hline \multirow{4}{*}{ Travel form } & Alone & 264 & $19.0 \%$ \\
\hline & With family members & 420 & $30.2 \%$ \\
\hline & With friends & 483 & $34.7 \%$ \\
\hline & Organized by your leader & 222 & $16.0 \%$ \\
\hline
\end{tabular}

\section{Results and Discussion}

\subsection{Tourists' perception on the service quality of Sheqi}

According to the five levels of frequency, the interval scale in the measurement of perceived quality is .8 , and the range of five levels of frequency is detailed in Table 2.

Table 2. Range of Five Levels of Frequency for Perceived Quality

\begin{tabular}{lll}
\hline Mean Range & Meaning & Reflect to \\
\hline $4.21-5.00$ & Strongly Agree & Highest degree of Agreement \\
$3.41-4.20$ & Agree & High degree of Agreement \\
$2.61-3.40$ & Basically Agree & Moderate degree of Agreement \\
$1.81-2.60$ & Basically Disagree & Low degree of Agreement \\
$1.00-1.80$ & Disagree & Lowest Agreement \\
\hline
\end{tabular}

The mean, standard error, and standard deviation of each item, and the means of the five dimensions of 
perceived quality and levels were presented in Table 3.

Table 3. Results of Descriptive Analysis of Perceived Quality (N=1389)

\begin{tabular}{|c|c|c|c|c|c|c|}
\hline Item & Mean & $\begin{array}{c}\text { Standard } \\
\text { Error of } \\
\text { Mean } \\
\end{array}$ & S.D. & Dimension & Mean & Level \\
\hline PQ1 & 4.030 & 0.026 & 0.977 & \multirow{7}{*}{ Reliability } & \multirow{5}{*}{3.988} & \multirow{5}{*}{ Agree } \\
\hline PQ2 & 3.960 & 0.026 & 0.978 & & & \\
\hline PQ3 & 3.990 & 0.026 & 0.958 & & & \\
\hline PQ4 & 3.990 & 0.026 & 0.977 & & & \\
\hline PQ5 & 3.970 & 0.026 & 0.970 & & & \\
\hline PQ6 & 3.960 & 0.026 & 0.984 & & \multirow{5}{*}{3.980} & \multirow{5}{*}{ Agree } \\
\hline PQ7 & 3.990 & 0.026 & 0.978 & & & \\
\hline PQ8 & 3.990 & 0.026 & 0.975 & \multirow[t]{4}{*}{ Responsiveness } & & \\
\hline PQ9 & 4.000 & 0.026 & 0.979 & & & \\
\hline PQ10 & 3.960 & 0.027 & 0.992 & & & \\
\hline PQ11 & 4.040 & 0.026 & 0.957 & & \multirow{5}{*}{4.012} & \multirow{5}{*}{ Agree } \\
\hline PQ12 & 4.000 & 0.026 & 0.981 & \multirow{4}{*}{ Assurance } & & \\
\hline PQ13 & 4.010 & 0.026 & 0.986 & & & \\
\hline PQ14 & 4.000 & 0.026 & 0.977 & & & \\
\hline PQ15 & 4.010 & 0.026 & 0.955 & & & \\
\hline PQ16 & 3.960 & 0.027 & 0.988 & \multirow{5}{*}{ Empathy } & \multirow{5}{*}{3.970} & \multirow{5}{*}{ Agree } \\
\hline PQ17 & 3.990 & 0.027 & 0.992 & & & \\
\hline PQ18 & 3.960 & 0.027 & 0.994 & & & \\
\hline PQ19 & 3.960 & 0.027 & 1.001 & & & \\
\hline PQ20 & 3.980 & 0.027 & 1.002 & & & \\
\hline PQ21 & 4.050 & 0.025 & 0.948 & \multirow{5}{*}{ Tangibles } & \multirow{5}{*}{4.018} & \multirow{5}{*}{ Agree } \\
\hline PQ22 & 4.020 & 0.026 & 0.957 & & & \\
\hline PQ23 & 3.990 & 0.026 & 0.971 & & & \\
\hline PQ24 & 4.010 & 0.026 & 0.967 & & & \\
\hline PQ25 & 4.020 & 0.026 & 0.956 & & & \\
\hline
\end{tabular}

The results of Table 3 showed that, respondents perceived the quality of services provided by the ancient town as desirable (with means from 3.960 to 4.050). And the most favorable services were PQ21 (reasonable guiding system), PQ11 (making tourists feel safe during travel), and PQ1 (well conserved historical sites of authentity and integrity). The services that respondents perceived as relatively poor involving the following items: the quality of the environment (air, noise, water environment, etc.) meets the requirement of AAAA standard, prompt service to tourists, abundant souvenir is available, giving tourists individual attention, employees can understand the needs of tourists, and having the tourist's best interest at heart. Basically, respondents perceived the tangible aspects of service as most desirable, followed by assurance aspects and reliability, the empathy aspects and responsiveness of employees and staff were in weak position relatively.

Therefore, to improve the service quality of Sheqi, measures should be taken to improve the environment of the ancient town. Besides, all staff and employees in the tourism industry should concern tourists and try their best to help each tourist to make them feel ease and comfortable during travelling. More shops provide all kinds of souvenir for tourists should open to meet their needs for shopping and to provide more employment for local people as well.

\subsection{The Influences of Demographics on Perceived Quality}

Tourists can be classified into different groups according to their gender, age, education,and other demographic characteristics. by comparing the perceptions of different groups of tourists, The needs of different segments can be identified, and administrations and managers of destinations could tailor marketing strategies for different market segments and make their campaigns more effective.

4.2.1 The Influence of Gender on Perceived Quality

As a physiological characteristic, gender has a great influence on consumer's values and preferences (Palan, 2001), which results in male tourists may have different perception on service quality of travelling from female tourists. $\mathrm{T}$ test was used to examine if male and female tourists have a significant difference in their perception on service quality provided by the ancient town. As is shown in Table 4, male and female tourists have no significant difference in their perception on service quality of the specific attraction. However, there was slight difference between the means of male tourists' perceived quality and female tourists'. Female tourists' perception on the service quality of the ancient town was slightly higher (mean $=4.020)$ than male tourists' (mean $=3.953$ ), which may indicate that the service in the ancient town was more in line with the expectations of female tourists or female 
tourists had lower expectation to the attraction than their male friends.

Table 4. Results of T Test of Difference of Gender on Perceived Quality ( $\mathrm{N}=1389)$

\begin{tabular}{c|c|c|c|c|c}
\hline Varible & Gender & Frequency & Mean & S. t. & t \\
\hline \multirow{2}{*}{ Perceived Quality } & Male & 672 & 3.953 & 0.970 & \multirow{2}{*}{-1.315} \\
\cline { 2 - 5 } & Female & 717 & 4.020 & 0.847 & \\
\hline
\end{tabular}

Note: $\mathrm{n}=1389 ; * * *$ indicates $\mathrm{P}<.001 ; * *$ indicates $\mathrm{P}<.01 ; *$ indicates $\mathrm{P}<.05$.

4.2.2 The Influence of Age on Perceived Quality

Generally, differences in ages mean differences in physical, psychological, income and travel experience (Ma, et al., 2009). One way ANOVA was employed to examine if tourists with different ages have significant difference in their perception on service quality provided.

The results of Table 5 show that tourists with different ages have significant difference in their perception on service quality. Tourists under 18 years old have different perceived quality from tourist aged 18 to 29 and tourists aged 30 to 39 . The perception on service quality of tourists under 18 (mean $=3.848$ ) is lower than perception on service quality of tourists aged 18 to 29 (mean $=4.051)$ and that of tourists aged 30 to $39($ mean $=4.031)$ significantly $(\mathrm{F}=2.283, \mathrm{p}<.05)$. The results indicates that tourists under 18 are not satisfied with the service quality of the ancient town and the attraction should provide the new generation with appealing services to attract the potential market segment.

Table 5. Results of one-way ANOVA of Difference of Age on Perceived quality ( $\mathrm{N}=1389)$

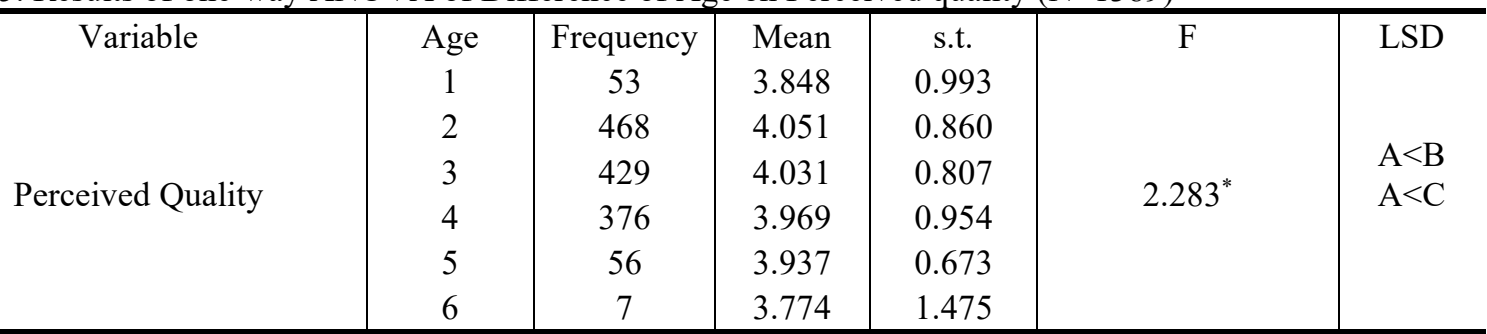

Note: $1=$ Under $18 ; 2=18-29 ; 3=30-39 ; 4=40-49 ; 5=50-59 ; 6=60$ and up. ${ }^{*}$ indicates $\mathrm{P}<.05$

4.2.3 The Influence of Monthly Income on Perceived Quality

The income level of tourists influences their buying power and may further influence their perceived quality. One way ANOVA was employed to examine if tourists with different monthly level have significant difference in their perception on service quality provided.

Table 6. Results of one-way ANOVA of Difference in Monthly Income on Perceived quality ( $\mathrm{N}=1389)$

\begin{tabular}{c|c|c|c|c|c|c}
\hline Variable & Monthly Income & Frequency & Mean & s.t. & F & LSD \\
& 1 & 958 & 4.023 & 0.872 & & \\
Perceived Quality & 2 & 204 & 4.053 & 0.898 & & $\mathrm{C}<\mathrm{A}$ \\
& 3 & 118 & 3.842 & 0.940 & $3.551^{* *}$ & $\mathrm{C}<\mathrm{B}$ \\
$\mathrm{E}<\mathrm{A}$ \\
\end{tabular}

Note: $1=$ Less than 3,000 Yuan; $2=3,000$ Yuan-4,999 Yuan; $3=5,000$ Yuan-7,999 Yuan;

$4=8,000$ Yuan-10,000 Yuan; $5=$ Above 10,000 Yuan. ** indicates $\mathrm{P}<.01$.

The results of Table 6 indicates that tourists with different monthly income have significant difference in their perception on service quality of the attraction. The perceive quality of respondents with monthly income of 5,000 to 7,999 Yuan (mean =3.842) and above 10,000 Yuan (mean =3.653) is lower than that of the respondents with monthly income of less than 3,000 Yuan (mean = 4.023) and 3,000 to 4,999 Yuan (mean = 4.053) significantly $(\mathrm{F}=3.551, \mathrm{p}<.01)$. Basically, tourists with higher monthly income are less satisfied with the services provided by the ancient town.

4.2.4 The Influence of Occupation on Perceived Quality

One way ANOVA was used to examine if tourists with different occupation have significant difference in their perception on service quality provided. The results are presented in Table 7. 
Table 7. Results of one-way ANOVA of Difference in Occupation on Perceived quality (N=1389)

\begin{tabular}{c|c|c|c|c|c|c}
\hline Variable & Occupation & Frequency & Mean & s.t. & F & LSD \\
& 1 & 60 & 3.982 & 1.081 & & \\
2 & 232 & 3.957 & 0.856 & \\
Perceived Quality & 4 & 11 & 3.697 & 1.432 & \\
& 5 & 25 & 4.093 & 0.764 & .326 & \\
& 6 & 24 & 3.968 & 0.962 & \\
& 7 & 47 & 3.698 & 0.607 & \\
& 8 & 3 & 3.730 & 1.101 & \\
& 9 & 876 & 4.001 & 0.882 & & \\
\hline
\end{tabular}

Note: 1 = Civil Servant; $2=$ Professional; $3=$ White-collar worker; $4=$ Blue-collar worker; $5=$ Service or trade staff; $6=$ Military reserve personnel; $7=$ Freelance; $8=$ the Retired; $9=$ Student $; 10=$ others

As is shown in Table 7, respondents with different occupations have no significant difference in their perception on service quality of the specific attraction. The mean of blue-collar workers' perception on the service quality of the ancient town is the highest, indicating that they are more satisfied with the services provided in the ancient town.

4.2.5 The Influence of Highest Education Level on Perceived Quality

The learning habit is formed after repeated practice in the learning process, and it will eventually develop into an automatic learning behavior needed by individuals. People with higher education background have a stronger tendency of automatic learning (Pizam \& Mansfeld, 1999). Therefore, tourists with different education background may have differences in the evaluation of tourism service quality due to their different learning ability. One way ANOVA was employed to examine if tourists with different highest education level have significant difference in their perception on service quality provided. The results are presented in Table 8 .

The results of Table 8 shows that respondents with Associated degree (mean $=3.842$ ) and Master's and Doctoral degree $($ mean $=3.653)$ have lower perception on service quality of the attraction than that of respondents with highest education level of less than $($ mean $=4.023)$ or equal to high school $($ mean $=4.053)$ significantly $(F=$ $3.561, \mathrm{p}<.01)$. Therefore, respondents with higher level of education have lower perceived quality for the attraction.

Table 8. Results of one-way ANOVA of Difference in Highest Education Level on Perceived quality (N=1389)

\begin{tabular}{c|c|c|c|c|c|c}
\hline \multirow{6}{*}{ Variable } & Highest Level of Education & Frequency & Mean & s.t. & F & LSD \\
& 1 & 958 & 4.023 & 0.872 & & \\
Perceived Quality & 2 & 204 & 4.053 & 0.898 & & $\mathrm{C}<\mathrm{A}$ \\
& 3 & 118 & 3.842 & 0.940 & $3.561^{* *}$ & $\mathrm{E}<\mathrm{A}$ \\
$\mathrm{C}<\mathrm{B}$ \\
& 4 & 47 & 3.970 & 0.843 & & $\mathrm{E}<\mathrm{B}$ \\
\hline
\end{tabular}

Note: $1=$ Less than high school; 2 = Equal to high school; 3 = Associate degree; 4 = Bachelor degree;

5 = Master's and Doctoral degree

\section{Conclusion}

The results of this study reveal that: 1) tourists have a high perception and evaluation on the quality of tourism service in Sheqi ancient town, especially the tangible and assurance aspects, services involving empathy and responsiveness are perceived have relatively low quality. 2) There are slightly more female visitors than male in the specific historical and cultural attraction, and their perceptions on the tourism service quality have no significant difference. 3) The majority of tourists were between age of 18 to 49, tourists with different ages have different perception on quality of tourism service. The new generation (under 18) perceived the quality of tourism service of the ancient town as lower than that of the tourists with age from 18 to 39. 4) It could be found that most tourists have at least three year of college education, and tourists with higher level of education have lower perceived quality. 5) Majority of the tourist with monthly income less than 5,000 Yuan, and tourists with different monthly income have significant difference in their perception on service quality of the attraction. Tourists with less monthly income have higher perceived quality than those with monthly income above 5,000 Yuan. And 6) Tourists with different occupations have no significant different perceived quality regarding the specific ancient town. It is also found that many tourists knew about the ancient town by recommendation of family and friends and visited it with their friends and family members.

The results of this study had managerial implications for the administration and managers of Sheqi ancient 
town to improve their tourism service quality. Firstly, much attention should be paid on staff training to make them keep tourists' needs and interests in mind. Only when all service personnel have service-minded, could they provide tourists with prompt responses and services and try their best to give each tourist individual attention. Meanwhile, special facilities and services for specific groups, such as the elderly, children and the disabled, should be provided in the attraction and shops selling abundant souvenirs should be opened to satisfy tourists' shopping needs. Secondly, as mentioned above, different segments of tourists have different perception of the service quality, indicating that they have different expectation and evaluation of the tourism service. Therefore, managers should take it into consideration, both tangible facilities and environments and intangible services should cater to the needs of the target tourists regarding different ages, income levels and highest levels of education.

There were some issues associated with the limitations of this study. In terms of research samples, owing to the limitations of the research objects, only tourists visited the small ancient town were surveyed, and most of the respondents coming from the same province, which may not be able to reflect the general conditions of historical and cultural attractions in China, even of the specific ancient town. Future studies may be conducted towards different historical and cultural attractions in different areas of China using large representative sample. Furthermore, this study profiles the status quo of the tourists' perception on tourism service quality of one ancient town in China, namely Sheqi, from demographic perspective using simple tools of descriptive analysis, $T$ test and one way ANOVA. The discrepancy between perceptions on tourism service quality of different demographic groups are found by the results of analyses, however, the specific factors and details of the discrepancy and the reasons results in the differences are not revealed in this study. Future studies may be conducted concerning the specific discrepancy between perceived quality of different demographic groups and the detailed reasons behind.

\section{References}

Aaker, D. A. (2009), Managing Brand Equity: Capitalizing on the Value of a Brand Name, New York: Free Press.

Baker, D. A., \& Crompton, J. L. (2000), Quality, satisfaction and behavioral intentions, Annals of tourism research, 27(3), 785-804.

Chen, C. F., \& Chen, F. S. (2010), Experience quality, perceived value, satisfaction and behavioral intentions for heritage tourists, Tourism management, 31, 29-35

Chen, C., \& Shi, H. (2008), A study of service quality and satisfaction for museums: Taking the national museum of prehistory as an example, The Journal of Human Resource and Adult Learning, 4, 159-170.

Chen, C.-C., Huang, W.-J., \& Petrick, J. F. (2016), Holiday recovery experiences, tourism satisfaction and life satisfaction: Is there a relationship? Tourism Management, 53, 140-147. Retrieved from www. https://doi.org/b6hk

Hsieh, C. M., Park, S. H., \& Hitchcock, M. (2015), Examining the relationships among motivation, service quality and loyalty: The case of the National Museum of Natural Science, Asia Pacific Journal of Tourism Research, 20, 1505-1526. https://doi.org/b6hn

Kang, G. D., Jame, J., \& Alexandris, K. (2002), Measurement of internal service quality: application of the SERVQUAL battery to internal service quality, Managing Service Quality: An International Journal, 12(5), 278-291.

Lam, S. S., \& Woo, K. S. (1997), Measuring service quality: a test-retest reliability investigation of SERVQUAL, International Journal of Market Research, 39(2), 381.

Ma, Y. F., Wang, G. X., Zhang, Y. Y., \& Wang, J. (2009), Tourism service perception and evaluation of domestic tourists to archaiccapital — Taking Xi'an for example, Journal of Arid Land Resources and Environment, 23(6), 176-180

Palan, K. M. (2001), Gender identity in consumer behavior research: A literature review and research agenda, Academy of Marketing Science Review, 10, 1-31.

Parasuraman, A., Zeithaml, V. A., \& Berry, L. L. (1985), A conceptual model of service quality and its implications for future research, The Journal of Marketing, 49, 41-50. https://doi.org/hjk

Parasuraman, A., Zeithaml, V. A., \& Berry, L. L. (1994), Alternative scales for measuring service quality: a comparative assessment based on psychometric and diagnostic criteria, Journal of retailing, 70(3), 201-230.

Pizam, A., Chon, K. S., \& Mansfeld, Y. (1999), Consumer behavior in travel and tourism. Psychology Press.

Randheer, K., Al-Motawa, A. A., \& Vijay, P. J. (2011), Measuring commuters' perception on service quality using SERVQUAL in public transportation, International Journal of Marketing Studies, 3(1), 21.

$\mathrm{Su}, \mathrm{L}$. , Swanson, S. R., \& Chen, X. (2016), The effects of perceived service quality on repurchase intentions and subjective well-being of Chinese tourists: The mediating role of relationship quality, Tourism Management, 52, 82-95. https://doi.org/b6j9

Wang, X. (2011), The effect of unrelated supporting service quality on consumer delight, satisfaction, and repurchase intentions, Journal of Service Research, 14, 149-163. https://doi.org/dsd7wc

Wang, X., \& Mei, H. (2006), Tourist satisfaction of tourism destination: model and empirical study, Journal of Beijing international studies university (tourism edition), 137,58-62 
Wu, H.-C., \& Li, T. (2015), An empirical study of the effects of service quality, visitor satisfaction, and emotions on behavioral intentions of visitors to the museums of Macau, Journal of Quality Assurance in Hospitality \& Tourism, 16, 80-102. https://doi.org/b6kb 